\title{
USO DA INTERNET COMO FERRAMENTA DE MEDIAÇÃO PEDAGOGICA NO ENSINO SUPERIOR DE GRADUAÇÃO E SUA POSSIBILIDADE DE SUBSTITUIR AS BIBLIOTECAS TRADICIONAIS
}

\author{
Ademir Gomes Ferraz \\ Universidade Federal Rural de Pernambuco, Brasil
}

\section{INTRODUÇÃO}

O atual momento, pelo menos nas Universidades Federais, é de saturação na relação aluno por professor. Este se apresenta incompatível com o desenvolvimento de um trabalho na qualidade requerida pela academia. Isso decorre tanto das políticas públicas para o setor, quanto da própria mudança da sociedade que não é mais a mesma da década de 70 , por exemplo. Alteraram-se não só a relação aluno por professor mas, também, os próprios interesses dos alunos, suas perspectivas e sua visão de mundo. $O$ ambiente histórico-cultural dos alunos desde a retomada da democracia, se vem fundamentando em novas formas de pensar, de agir e de buscar alternativas para a construção do seu conhecimento.

A partir do contato com as Novas Tecnologias de Ensino - NTEs ou novas Tecnologias de Informação e Comunicação - NTICs, gerou-se na sociedade de modo geral e nas Universidades de modo particular, um ambiente de expectativa, muitas vezes a partir de professores (ou facilitadores) que, deslumbrados com as possibilidades deste conjunto de meios no auxilio de seu fazer cotidiano, equivocadamente, os imaginaram como elementos que vieram para facilitar o seu trabalho. De acordo com Vieira isso seria uma atitude Behaviorista onde "aprender se resumiria a exibir comportamentos apropriados" Vieira[1].

Neste trabalho pudemos verificar a exigência de elementos chaves a serem levados em consideração quando se pretende utilizar a internet no ensino, bem como levantamos alguns dados que indicam ser a internet, nos dias de hoje, o elemento das Novas Tecnologias do Ensino, mais usado pelos docentes em busca da interação aluno-professor na direção defendida por Vygotsky quanto à construção do conhecimento.

Finalmente vimos contribuir com outros trabalhos como o de Moran[2], Bartolomé[3] e Clarck[4] ao discutirmos a utilização da internet no ensino presencial em vários aspectos.

\section{O COMPUTADOR / INTERNET.}

A nova forma de aprender e de "ensinar"1 trazida pelo computador, levanta questões onde: de um lado estão os "neófitos" e de outro os "neófobos". Os primeiros acham que as Novas Tecnologias de Ensino - NTEs, são a solução para todos os males da educação, os segundos acham que não passam de modismo e que por isso devem ser esquecidas. Do nosso ponto de vista devemos dispensar os extremos, ou seja: Nem uma coisa nem outra. Os computadores como parte das NTEs e por onde temos acesso ao que nos interessa no momento, a Internet, não são soluções para todos os males nem podem ser esquecidos - $O$ que, de certa forma, fizemos com a televisão e o rádio.

\footnotetext{
${ }^{1}$ Aspas porque do nosso ponto de vista professor apenas orienta, sugere
} 
Eles podem ajudar, a partir de alguns elementos que amparem sua utilização no ensino. Abrem a possibilidade para que possamos utilizar outras práticas pedagógicas sem, contudo, significar que dessa forma os alunos aprenderão mais rápido ou "melhor". Moran[2] afirma: "A tecnologia permite um novo encantamento com a escola, ao abrir suas paredes e possibilitar que alunos e professores compartilhem seus conhecimentos". Moran está contextualizando, exatamente, o fato de que a internet não está posta para que o aluno aprenda "melhor" ou mais "rápido". Mas sim que ela pode promover a interação entre os agentes do ensino na direção da aprendizagem coletiva.

Ao se referir ao aprendizado através de "antigos" e de "novos" meios de ensino, Clarck[4] ${ }^{2}$ afirma: "Somente se encontra um efeito muito pequeno e positivo para os meios mais novos frentes aos meios convencionais (pg. 448)". Neste mesmo sentido, Bartolomé[3] se utiliza o trabalho de Kulik [Kulik y Ot., 1983] para informar que não há diferença substancial no aprendizado utilizando-se a internet frente aos meios tradicionais. De acordo com os estudos citados por Bartolomé, os pesquisadores, "realizando uma meta-análise de $\mathrm{CBI}^{3}$, encontraram um tamanho de efeito de 0'51. Porém este se reduzia a 0'13 quando era um mesmo professor que planejava e ensinava a ambos grupos, experimental e controlado" (Bartolomé[3]). Isso em uma escala de 0 a 10.

A realidade que encontramos em nossa aplicação, aparece amparada por diversos pesquisadores como, por exemplo, Lévy quando coloca o professor como um incentivador. De acordo com Lévy o professor "... tornar-se um animador da inteligência coletiva de seus grupos de alunos em vez de um fornecedor direto de conhecimentos" (Lévy [5]). E, nesse caso, não é o computador que servirá como fonte de estímulo. Ele não é o mediador proposto por Vygotsky[6]. Esta tarefa é do professor sujeito indispensável no processo.

Utilizar o computador de modo geral e a internet de modo particular, não significa trocar o giz e a lousa pela tela e o mouse. Significa, principalmente, ter de mudar de atitude: o professor não pode mais agir na forma tradicional onde o aluno é apenas um sujeito passivo do processo - Ele precisa "saber" - e isso não se dá pelo simples uso da internet. A mudança necessária do professor se faz em qualquer ambiente, pois não é o ambiente que precisa mudar: é a mentalidade no dizer de Mayer com respeito à "introdução de conceitos e habilidades e competências", Mayer[7] et all, onde levanta que precisamos discutir o problema do "saber" e do "saber fazer".

A internet entra no processo como uma ferramenta a mais e, mais ainda, a mais indicada na solução do problema causado pela explosão demográfica definida aqui como, cada vez maior, o número de alunos por professores nas Universidades Públicas.

\section{A IDÉIA, A CONSTRUÇÃO DA APLICAÇÃO E O QUE BUSCAMOS.}

A idéia da aplicação foi levantar, em nível da UFRPE, quais os problemas enfrentados pelos professores e alunos se pretendiam utilizar a internet no ensino e se a internet, através das bibliotecas online, poderia ser um suplemento, ou mesmo uma substituição, à biblioteca tradicional; a nível mais amplo,

\footnotetext{
${ }^{2}$ Disponivel, em parte, em www.educause.edu/nlii/clark.html (Em inglês)

${ }^{3}$ Medida de aprendizagem baseada em computador
} 
verificar quais os requisitos necessários para que se possa utilizar com sucesso a internet no ensino presencial de graduação e qual o comportamento dos professores e alunos envolvidos.

Na pesquisa envolvemos dois professores e dois cursos: Licenciatura em Matemática e Licenciatura em Física. No caso da física abordamos a Origem da Teoria Quântica - OTQ. No caso da matemática o tópico René Descartes - RD.

O professor responsável pela turma "OTQ" possui todas as condições para trabalhar com a internet já tendo ministrado curso a distancia ${ }^{1}$, enquanto o professor da turma "RD" não tinha o menor conhecimento da utilização da internet nem para fins pessoais.

Seguimos o seguinte direcionamento: Cada aluno foi cadastrado em um fórum tipo mural contratado em um site que oferece os serviços. No primeiro momento foi passado para todos as necessárias habilidades na utilização, e a forma de como se daria o projeto durante 1 mês. Não poderíamos utilizar mais do que isso uma vez que este era o tempo previsto para que os professores ministrassem os tópicos respectivos. Os alunos foram incentivados pelos professores a visitarem sites específicos. No caso da turma $\mathrm{RD}$ o pesquisador indicou alguns "sites" dada a não afinidade do professor da disciplina com a internet.

$\mathrm{Na}$ segunda-feira em que iniciamos o projeto, os alunos freqüentaram a aula em sala tradicional a fim de rediscutimos todo o processo. A partir daí, nas sextas-feiras à noite, os alunos da turma "OTQ" passaram a utilizar o Laboratório da Biometria e os alunos da turma "RD", o Laboratório do curso de Engenharia de Pesca. Nas segundas-feiras os alunos da turma "RD" discutiriam em grupo sem a intervenção do professor. Enquanto os alunos da turma "OTQ" fariam a discussão com a mediação do professor.

De modo geral deveriam tratar: do que foi encontrado durante a semana, que problemas ocorreram e que opinião eles teriam a respeito do andamento do projeto. Durante o dia, por toda a semana, a partir de acesso de fora da instituição, eles deveriam pesquisar, contatar-se entre si, via e-mail, e postar questões no fórum. Nas sextas-feiras debatiam tudo no laboratório, via internet, numa espécie de Chat. Assim tinha-se o momento presencial-síncrono pois dentro do mesmo laboratório e os momentos não-presenciais e assíncronos pois de fora do ambiente coletivo.

\section{FUNDAMENTAÇÃO TEÓRICA}

Para Vygotsky[6] a pessoa aprende sozinha até certo ponto a partir do qual necessita de outras que saibam mais a fm de evoluir no seu aprendizado. A interação, portanto, é fundamental em sua teoria. Vygotsky apud Oliveira[9] afirma que: "É pela APRENDIZAGEM nas relações com os outros que construímos os conhecimentos que permitem nosso desenvolvimento mental".

Podemos ainda apoiar a fundamentação buscando Demo que discute ter a aprendizagem como centro principal não apenas repetir "conhecimento" mas "também forjar o indivíduo capaz de ser o dono de seu conhecimento, ser autônomo em seu conhecimento".(Demo[2])

De acordo com a teoria de Vygotsky isso não é de todo possível nos indivíduos que vivam afastados do meio histórico-cultural prescindindo da troca com outros indivíduos. Vygotsky apud Fernandes[8] e Fernandes ${ }^{1}$ "considera que o caminho do desenvolvimento do pensamento no indivíduo vai no sentido do

\footnotetext{
${ }^{1}$ Formação continuada de professores pelo PROINFO
} 
social para o individual. Para ele, o conhecimento depende, fundamentalmente, da adaptação à realidade externa"(Fernandes[8] \& Fernandes).

Rego afirma: " as funções psicológicas especificamente humanas, originam-se nas relações do indivíduo e seu contexto cultural e social"(Rego[11]). Nesse caso a cultura é parte integrante da natureza humana onde o homem funciona como um organismo biológico. Este organismo humano não pode ser afastado do ambiente cultural sob pena de perder sua humanidade.

A participação do aluno no projeto em que ele pôde, na atual circunstância, discutir de modo mais constante com outros alunos e com o professor sem que, necessariamente, ocupassem o mesmo espaçotempo, mostra a importância da internet no ensino presencial.

Para atender a este projeto precisávamos manter uma estrutura na qual estivessem contemplados alguns elementos considerados por Fernandes[8] \& Fernandes no seu trabalho com enfoque na a Educação a Distância $(E A D)^{1}$. No entanto um dos objetivos foi o de verifica a necessidade, ou não, de um modelo pedagógico a sustentar o trabalho. Por isso não contemplamos o modelo.

\section{METODOLOGIA}

A consecução do projeto teve como etapas iniciais as seguintes:

1 - Questionário.

No questionário perguntávamos quais alunos desejavam participar do projeto esclarecido que não haveria o "estímulo" de notas, por exemplo. Todos desejavam participar. Também identificamos quais alunos possuíam acesso à internet fora da Universidade. Neste caso, considerando-se as duas turmas, a média, nestas condições, foi de 40\%. Sendo 50\% na turma "OTQ" e 30\% na turma "RD". O questionário ainda buscou saber quais dos alunos tinham o conhecimento suficiente para participar do projeto. Apesar de não podermos trabalhar com os mesmos critérios com alunos com acesso e sem acesso fora da instituição, preferimos cadastrar todos nos fóruns e nas listas de discussão.

Mapeamos, para estudo, apenas aqueles que possuíam acesso tendo em vista as dificuldades impostas pelo tempo que teríamos para dedicamos a este trabalho. Dessa forma nosso resultado refere-se ao universo de alunos que possuíam acesso a internet fora da instituição - 80 alunos.

\section{DESENVOLVIMENTO E OCORRÊNCIAS.}

Foi do nosso interesse não interferir no processo no transcorrer dos trabalhos. Um estudo seria feito baseado nas informações do professor. Elas poderiam ser escritas ou verbais, e apoiado nos "e-mails" e listagem das questões postadas no fórum.

O professor responsável pelo trabalho no Tópico "RD", comunicou não haver percebido diferença de aprendizagem durante o processo. Ainda que o objetivo do trabalho não fosse "medir" a aprendizagem, essa foi uma importante informação uma vez que se vem ajustar com a pesquisa de Kulikan et all citado por Bartolomé [3] e ao trabalho de Clarck[4].

Tanto o professor responsável pela turma "OTQ", quanto o professor responsável pela turma "RD" mantiveram contato conosco, pessoalmente, buscando informações sobre o andamento do projeto. Em 
todas as oportunidades buscamos não entrar em detalhe sobre o desenrolar do fórum e da lista, uma vez que essas informações, passadas ao professor, poderiam interferir no andamento dos trabalhos além do que queríamos "medir" o cumprimento do professor com o projeto. Um dos pontos traçados nos objetivos cobrava uma comparação entre: Um grupo de alunos orientados por um professor de alta competência de conteúdo, mas que não domina a ferramenta internet, e um grupo de alunos orientados por um professor de alta competência de conteúdo e com total domínio dessa ferramenta.

Um dado importante seria o esperado relato, verbal ou por escrito, do professor da turma "OTQ". No entanto isso não foi possível. Esse fato, paradoxalmente, foi de alta relevância para nossas conclusões. Ele veio responder tanto a questão do projeto pedagógico, que exige a atenção do professor, quanto à questão da competência existente no uso da Internet.

O processo encerrou-se em Fevereiro / 03. Com base nos dados do fórum e das listas, pudemos fazer todo nosso levantamento e respondermos nossas questões reconhecendo que, especificamente nesse caso, o relato do professor da turma "OTQ" nos poderia trazer informações importantes para outro estudo. Pelo disposto no fórum, somos levados a acreditar que os dados poderiam contribuir fornecendo subsídios a outro artigo por nós pretendido, algo que somente agora vislumbramos.

\section{Fórum René Descartes}

O fórum René Descartes foi criado em 17/01/03 no endereço ¡Error!Marcador no definido.. O site ¡Error!Marcador no definido. é um site privado que comercializa diversos tipos de hospedagem. Para este trabalho o contratamos por 30 dias. A importância que o tema desperta está sugerido no fato de que, mesmo findo o contrato em 17/02/03, de comum acordo com a empresa, os fóruns (renedescartes e teoriaquantica) que deveriam sair do "ar" continuam até a presente data ${ }^{1}$. Possivelmente pelo número de acesso. Em 17/02/03, foi aberto ao público em geral. As mensagens colocadas aqui estão na integra. Até aquela data foram postadas mensagens como:

1) 1 - Me mandem a obra de René Descartes "O discurso do Método " ainda hoje por favor estou precisando. Desde ja muito obrigado

2) 2 - Quero receber tudo que fale sobre René Descartes e outro assunto envolvido. Se possível ainda hoje. Grata, Mariana

3) 3 - gostaria de receber o quanto antes sobre discuros e métodos

4) 4 - necessito fazer uma pesquisa completa sobre Descartes e agradeço a toda ajuda prestada .

Mensagem dos Alunos

As mensagens, nesse fórum, foram basicamente iguais às de título: René Descartes; René Descartes (Parte I); O homem também errava; RD; René, etc. Das 49 mensagens postadas no fórum até a data prevista para o termino do projeto, 34 foram dos alunos e 3 do pesquisador. As demais foram de pessoas que acessaram ao ser liberado.

\footnotetext{
${ }^{1}$ www.abed.org.br/texto32.htm

1 http://inforum.insite.com.br/teoriaquantica/ 
Percebe-se, por parte do alunado, questões informativas. Se por um lado isso vem sugerir a forma como o tópico é apresentado, discursivamente, e sobre a bibliografia de René Descartes, por outro percebemos que os alunos não percebem que o ato de recortar e colar é de fácil percepção. Isso vem sugerir, mais uma vez, a importância do professor na aquisição da competência que é a utilização das NTEs de modo geral e da internet de modo particular.

Os alunos partem do principio de que o professor não conhece o mecanismo e, assim, "vale" a lei do menor esforço. Não se preocupam com a ética e as normas legais de citações.

Percebemos não ter havido a tentativa de se compreender a obra de Descartes. O aluno apenas navegou, achou artigos, recortou e colou. O lado positivo na turma foi o de verificarmos que, mesmo com a ausência (proposital) de qualquer professor, eles foram ao laboratório, em um local bastante afastado de onde sempre viveram na Instituição e nos dois últimos horários da sexta-feira onde é "cultural" a falta às aulas. Mais do que isso: Chegavam no horário certo e queriam ficar "mais um pouco". Podemos considerar, no caso desta turma, que o "trabalho" era um mero passa-tempo.

Não desconhecemos o deslumbramento de que falou Paulo Gileno em Palestra no Mestrado em Ensino das ciências na UFRPE. Mas temos conosco a idéia de que o encantamento pode ser positivo. $O$ aluno entra na universidade deslumbrado, compete a Instituição não o decepcionar, fazer com que os excessos sejam "expurgados" sem que esse deslumbre se transforme em frustração e a oportunidade em passa tempo.

\section{Fórum Origem da Teórica Quântica}

Da mesma forma observamos que o tópico é de grande importância. O que chamamos a atenção sobre a hospedagem do fórum "renedescartes" vale, de modo integral, para o fórum "teoriaquantica". Foi criado em 21 de Janeiro de 2003, fechado (permissão somente para os componentes do projeto) e foi aberto ao público em 21/02/03. O ocorrido depois de aberto ao público seguiu os passos do fórum René Descartes.

As questões postadas pelos alunos não obtiveram respostas do professor. Provavelmente o tenha feito em sala de aula. O que fugiu da idéia principal que era a importância da comunicação via fórum complementada em sala. As respostas em sala são positivas, no entanto deveriam ser postas na página onde, mesmo que o aluno faltasse à mesma, pudesse acessar. Quanto à lista não teve movimento considerável.

As perguntas, neste fórum, foram objeto de debates. Percebemos, aqui, a influência do professor. Seja por orientar os alunos a promoverem discussão, seja pelo enfoque dado na disciplina, seja pelo fato dos alunos saberem que o mesmo tinha grande afinidade com a internet.

\section{Algumas Mensagens dos Alunos}

Essas questões são interessantes por pelo menos dois motivos:

- $\quad$ algumas foram postadas por pessoas não cadastradas, e respondida por aluno cadastrado o que mostra um interesse / preocupação mais geral;

- houve, de fato, debate entre os alunos e aprofundamento de questões ainda em abertas na Física. 
A importância ainda é maior por percebemos que a interação foi alem do tempo proposto para a pesquisa. Isso vem sugerir que os alunos ainda têm interesse no debate. Infelizmente o professor não pode abrilhantar o mesmo certamente por sua elevada carga de trabalho.

Preservamos as mensagens na forma como postadas até para que se possa perceber que não se tratou de recortar e colar mas sim de digitação ou de desconhecimento da língua. O que não retira o mérito do debate. Assim como ocultamos alguns endereços e nomes devido ao excesso de erros de ortografia. Outros endereços são colocados uma vez que os erros são aceitáveis.

Data: 16/05/2003 23:18

De: Jaqueline (;Error!Marcador no definido.) \{Não pertencia ao grupo\}

Assunto: Origem da eletricidade

eu queria saber qual é a origem da eletricidade?

\section{De: A Sena \{Preservado com a ocultação\}}

Assunto: Re: Origem da eletricidade

Origina-se na época dos gregos, com a percepção de que alguns objetos atraião outros, a eletrização foi um dos pricipais tema durante muito tempo. O que fazia um atrair o outro, porque e qual a relação entre eles, para isto ocorre. Como a eletricidade numca deixo de existir no passado, pressente e futuro, apergunta agora é porque demorou tamto para ser melhor estudada. Pelo simple motivo de não haver equipamentos na época, exemplo muito importante como a batiria e posteriore a bobina para aplificar a corrente. Pois graças a estas invençoes foi que se pode analizar a corrente em laboratório e verificar outras propriedades intriscicas da onda eletromagnetica.

\section{De: Frederico Augusto (faosı@msn.com) \{Não pertencia ao grupo\}}

\section{Assunto: Me desculpem}

Me desculpem pelos erros, pois são $3 \mathrm{~h} 15 \mathrm{~min}$ da manhã estou c/ sono mas a química quantica me intriga, principalmente por não ter bagagem sobre esse assunto, me interesso muito por física, fiz um curso de Astronomia e algumas ou pq não a maioria das Explicações se baseiam em teses sobre os grandes físicos... e agora entro em um assunto um pouco delicado, pq li em uma máteria de revista, onde eles relacionam o fenômeno Poltergeist com a Mecânica Quântica e a metafísica e não vi o menor sentido da associação de um com o outro, pelo que eu lí sobre oq vcs conversaram até hj, ela é extremamente limitada a Física, não sei até onde repito não tenho como discutir oq não sei, mas em Módulo Cetiris Paribus não entendo onde esta a relação do campo de Física c/ este fenômino, alias se houver o interesse de vcs posso escaniar a máteria e dar o nome dos cientistas q fazem essas teses não posso chamar assim pq não sei de que ponto ciêntifico eles tiraram isso, então peço a ajuda de vcs para resolver este dilema.

\section{De: Altenis}

\section{Assunto: Re3: ONDA OU PARTÍCULA?}

Gilvan o elétron é uma partícula. O experimento de Thomson mostrou isto. O difícil como você mesmo falou é entender o elétron como uma onda. Eu ainda não entendi, mas já aceitei, contudo ainda que entender. Compreende? 
A questão também é filosófica. Até a mecânica clássica de Einstein tudo era bem determinado, se soubessemos as condições iniciais de um sistema saberíamos sua configuração em qualquer instante posterior. Isto era conhecido como o Determinismo. Depois desta tal Mecânica Quântica este determinismo deixou de existir e nem Einstein compreendeu direito este indeterminismo dizendo: "Deus não joga dados."

Isto me faz pensar se não estamos tão ligados a nossa velha Mecânica Clássica e nos perguntando, onde está o elétron?

O Einstein afirmava que o indeterminismo se dava pelo fato de não conhecermos todas as variáveis do sistema. Com isso ele afirmava(creio eu) que a Mecânica Quântica estava incompleta, pra não dizer errada, por isso, a Quãntica seria indeterministica. Quem sabe? Só o futuro poderá dizer se voltaremos para o determinismo. Mas por enquanto a Mecânica Quântica tem funcionado muito bem(É o que dizem).

\section{CONCLUSÃO.}

Ao observarmos os extravagantes erros ortográficos dos alunos da turma OTQ, parece-nos paradoxal que esse erros nos aponte para algo realmente importante: Os alunos escreveram de acordo com seus conhecimentos, dos entendimentos do que foi lido, dos conflitos existentes. Tudo isso levou a grande debate mostrando, de fato, a Internet e sua importância enquanto meio de pesquisa e de interação.

Quando analisamos as mensagens dos alunos da turma RD, vemos um altíssimo grau de correção tanto ortográfica quanto de conhecimento sobre o tema. Temos mensagens com até 60 linhas absolutamente corretas em seu todo: contexto, ortografia, análise do conteúdo, etc. Por via do professor e através de nossa experiência acadêmica com esses alunos podemos, com o mínimo de risco possível, afirmar que eles utilizaram o recorta e cola sem maiores preocupações. E é ainda relevante frisar que não se trata de caso isolado: Todos os alunos da turma RD assim se comportaram.

Apesar de nossa "certeza" fizemos uma reunião com os alunos dos dois grupos esclarecendo que não haveria prejuízo de seu trabalho qualquer que fosse a informação. Não foi, portanto, surpresa que nossa avaliação e a do professor estivessem correta: $100 \%$ dos alunos nas duas turmas confirmaram o que já comentamos: A turma RD uso do recortar e copiar enquanto a turma OTQ estudo e discutiu. Ficou, para essa turma, o alerta sobre a ortografia. De toda forma todos nos participantes pudemos aprender com os acertos e com nossos erros. E, inegavelmente, aplicação foi de grande relevância para nossa dissertação de mestrado que hora se encontrava em andamento.

Vemos que o uso da internet no ensino presencial se torna relevante face vários fatores como a inexistência de tempo a uma maior interação entre os alunos e os professores. Pudemos extrair, entre outros dados, que: não é suficiente professores e alunos acreditarem nesta ferramenta como importante para o ensino e mais; é importante que professores e alunos saibam lidar com o computador / Internet; no entanto, isso também não é suficiente.

- Que ambos acreditem na Internet enquanto ferramenta colaborativa;

- $\quad$ que ambos saibam utilizar a ferramenta;

- que o professor não a veja como usurpadora do seu espaço e;

- que esta utilização esteja prevista na proposta pedagógica cobrando responsabilidades. 
A abordagem vem sugerir a importância de que o professor deva possuir a competência suficiente no trabalhar com a internet. Verificamos isso ao compararmos como as duas turmas se comportaram em termos de utilização da internet dentro de condições semelhantes.

O fato de que aluno tenha de se deslocar de seu ambiente normal de estudo, é significativo ainda que a Universidade seja um espaço plural devendo ser utilizada em sua totalidade. A questão é que o deslocamento se dava para local inóspito (Falta de iluminação, de segurança, de maior comodidade).

O fato de o investigador ter de solicitar permissão para levar a efeito seu trabalho, em laboratórios não destinado a este fim, mostra a dificuldade de acesso pela carência de máquinas. Outro problema reside na falta de um plano pedagógico que seja parte integrante da disciplina.

Percebemos que o professor tem várias dificuldades se deseja implementar o uso da internet em sua disciplina. Uma dessas dificuldades é reconhecer que a internet não the vai liberar tempo. Ou seja, utilizar a internet imaginando poder ter mais tempo para outras tarefas é um engano. $O$ uso da internet vai cobrar mais tempo do professor do que quando da abordagem presencial sem o suporte da mesma.

Finalmente a aplicação nos mostra que a internet pode auxiliar na solução para problemas causados pela explosão demográfica ao servir como meio de interação entre alunos e professores além de ser uma opção, pelo menos aos alunos trabalhadores, à biblioteca tradicional em suas pesquisas. $\mathrm{O}$ aluno a pode fazer a qualquer hora, de qualquer lugar de onde possa ter acesso à rede mundial de computadores.

\section{BIBLIOGRAFIA}

BARTOLOMÉ[3], A.___ Mensagem Pessoal enviada para o autor. Assunto:

Repuesta a Http://www.imi.ub.es/personal/bartolome/enviarMensagem.html

Data: 20 de outubro de 2002 às $21 ; 30 \mathrm{~h}$

abartolome@imi.ub.es

CLARK[4], R.E. Reconsidering Research on Learning from Media. Review of

Educational Research (1983, p. 445-459).

Demo[2], P. Educar é diferente de ensinar. Jornal do Brasil. Rio de Janeiro. Caderno Empregos. 08/outubro/2000 - p. 1.

FERNANDES[8] e Fernandes___ Metodologia Construtivista Usando um Ambiente de Software Baseado na Intenrnet.

Acessado em Setembro de 2003

Reacessado em 30 de Novembro de 2003 às 10:30 hs

ABED - VIII Congresso

LÉVY[5], P. 1956 - As tecnologias da Inteligência /Pierre Lévy: Tradução

L65T de Carlos Irineu Costa -Rio de Janeiro: ED 34, 1993208 p.(Coleção TRANS)

MORAN2], J.M. Como Utilizar a Internet na Educação

Acessado em: 2002 
Recessado em: 01 de Agosto de 2003.

MAyer[7],M., Bastos, H.,Costa,S.,Numeriano,J. - Ensino De Ciências Em Ambientes Virtuais: A Percepção Do Professor Sobre As Diferenças Na Sua Prática Introduzidas Pelo Uso Das Novas Tecnologias

Revista brasileira de Pesquisa em Educação em Ciências, i(l)132-139,2001

OLIVEIRA[9], Marta Kohl de. Vygotsky: aprendizado e desenvolvimento um

processo sócio-histórico. 3. ed. São Paulo: Scipione, 1995.

REGO[11],T.C.-Vygotsky: uma pespectiva teórico-cultural da

educação

Editora Vozes Itda, 1994, p. 41-43

VIEIRA[1] VIEIRA,F.M.S__ A Utilização das Novas Tecnologias na Educação numa Perspectiva Construtivista - 22aㅡ Superintendência Regional de Ensino de

Montes Claros Núcleo de Tecnologia Educacional - MG7 - Prolnfo - MEC

Acessado em Junho de 2002

Reacessado em 18 de novembro de 2003 às 17:30

VYGOTSKY[6], L.S. A formação social da mente : o desenvolvimento dos

processos psicológicos superiores, org. Michael Cole et al. Tradução José Cipolla Neto, Luis Silveira Menna Barreto, Solange Castro Afeche, 4. ed. São Paulo: Martins Fontes, 1991. 


\title{
Contactar
}

Revista lberoamericana de Educación

\author{
Principal OEI
}

